\title{
Does an Analysis of the Pulsatile Secretion Pattern of Adrenocorticotropin and Cortisol Predict the Result of Transsphenoidal Surgery in Cushing's Disease?
}

\author{
MICHAEL BUCHFELDER, RUDOLF FAHLBUSCH, HOLGER WENTZLAFF- \\ EGGEBERT, GEORG BRABANT, GÜNTER K. STALLA, AND OTTO A. MÜLLER \\ Neurochirurgische Klinik der Universität Erlangen-Nürnberg, D-91054 Erlangen; Abteilung für \\ Endokrinologie der Medizinischen Hochschule Hannover, D-30625 Hannover; and Medizinische Klinik \\ Innenstadt der Universität München, D-80336 Munich, Germany
}

\begin{abstract}
The endocrinological, surgical, and histological findings of patients with ACTH-dependent Cushing's disease were correlated with the pulsatile secretion pattern of ACTH and cortisol and the outcome after transsphenoidal pituitary surgery. A total of 28 patients were studied. The preoperative pulsatile secretion of ACTH and cortisol was assessed by sampling blood at 20 -min intervals over $24 \mathrm{~h}$. The pulsatile pattern of secretion was analyzed by the Cluster program. In 21 patients, an ACTH-secreting pituitary adenoma was identified and resected. Of these patients, 18 underwent clinical remission, and their cortisol secretion was suppressed to a normal level by low dose dexamethasone.
\end{abstract}

Histological examinations in the patients with persistent disease revealed normal pituitary in 6 cases, nodular hyperplasia in 1, and ACTHsecreting pituitary adenoma in 3 cases. Analysis of the pulsatile pattern of ACTH and cortisol secretion did not reveal significant differences in timing, frequency, and/or amplitude of ACTH and cortisol pulses in normalized patients and those with persistent disease after surgery. It is concluded that analysis of the secretory pattern is not a suitable method for predicting the outcome of transsphenoidal surgery in patients with ACTH-dependent Cushing's disease. ( $J$ Clin Endocrinol Metab 77: 720-724, 1993)
$\mathrm{I}^{\mathrm{T}}$ T IS WELL established that functional endocrine testing of the hypothalamic-pituitary-adrenal axis allows confirmation of the diagnosis of Cushing's syndrome and differentiation between ACTH-dependent pituitary disease (Cushing's disease) and hypercortisolism due to either ectopic ACTH-secreting neoplasia or cortisol-secreting adrenal tumors. Cushing's disease, however, may be the result of an autonomous ACTH-secreting pituitary tumor or hypothalamic dysfunction. Clinically, it is important to be able to distinguish between these two etiologies, because patients with hypothalamic dysfunction do not benefit from transsphenoidal surgery, whereas ACTH-secreting pituitary tumors are clearly best treated by this approach.

Preoperative differentiation between pituitary and hypothalamic disease cannot be achieved by standard biochemical investigations such as dexamethasone suppression tests (1) or stimulation tests with lysine vasopressin, insulin-induced hypoglycemia, or CRH (2). Neuroradiological examinations are also not particularly helpful in differentiating the entities, because in the majority of cases of Cushing's disease, minute microadenomas do not produce major abnormalities in images of the sella turcica region, and only about $50-60 \%$ of these small tumors within the gland are directly depicted by magnetic resonance scanning or computerized tomography. In an attempt to find biochemical differences between patients with hypothalamic disease and patients with pituitary

Received September 24, 1992. Accepted May 11, 1993.

Address all correspondence and requests for reprints to: Priv.-Doz. Dr. Michael Buchfelder, Neurochirurgische Klinik der Universität Erlangen-Nürnberg, Schwabachanlage 6, D-91054 Erlangen, Germany. tumors, van Cauter and Refetoff (3) analyzed literature data on the episodic secretion of cortisol in patients with Cushing's disease and correlated them to the different etiologies of Cushing's syndrome. Careful examination of the collected data suggested that a hypopulsatile secretion pattern of cortisol occurred in patients with autonomous ACTH-secreting pituitary tumors, whereas hyperpulsatile cortisol secretion was correlated with hypothalamic dysfunction. Based on their findings, the researchers proposed that differentiation of the two subgroups of patients with Cushing's disease may be possible by assessing the pulsatile profile of cortisol and ACTH. If this hypothesis is correct, the clinical implications are obviously of high significance. The purpose of the present study was, therefore, to further examine pulsatile ACTH and cortisol secretion patterns in patients with Cushing's disease and to correlate these to the surgical findings and the outcome of pituitary microsurgery.

\section{Subjects and Methods}

Between 1986 and 1989, 35 patients underwent transsphenoidal surgery as the primary treatment for Cushing's disease in the Department of Neurosurgery, University of Erlangen-Nürnberg. All had clinical evidence of hypercortisolism. Twenty-eight (23 females and 5 males) gave their informed consent to undergo a $24-\mathrm{h}$ sampling of peripheral venous blood in $20-\mathrm{min}$ intervals. All of the patients received routine preoperative endocrinological testing for the differential diagnosis of Cushing's syndrome, as described previously (4). Included was overnight testing with low $(2 \mathrm{mg})$ and high dose $(8$ and $16 \mathrm{mg}$, respectively) dexamethasone suppressibility and determination of cortisol and ACTH levels before and after iv CRH administration. Table 1 compiles the results of preoperative dynamic testing. Of 17 patients with negative imaging studies, 10 had simultaneous venous blood sampling from the 
TABLE 1. Results of the preoperative dynamic endocrine tests

\begin{tabular}{|c|c|c|c|c|c|}
\hline \multirow[b]{2}{*}{$\begin{array}{l}\text { Patient } \\
\text { no. }\end{array}$} & \multicolumn{3}{|c|}{ Dexamethasone suppression } & \multicolumn{2}{|c|}{ CRH stimulation } \\
\hline & $\begin{array}{c}\text { Cortisol } \\
\text { (nmol/L) } \\
\text { DST } 2 \mathrm{mg}\end{array}$ & DST $8 \mathrm{mg}$ & DST $16 \mathrm{mg}$ & $\begin{array}{c}\text { Cortisol } \\
\text { (nmol/L) }\end{array}$ & $\underset{(\mathrm{pmol} / \mathrm{L})}{\mathrm{ACTH}}$ \\
\hline 1 & $607 / 212$ & $/ 96$ & & $1158 / 1986$ & $11.0 / 23.8$ \\
\hline 2 & $632 / 640$ & $/ 69$ & & $772 / 2152$ & $4.6 / 8.5$ \\
\hline 3 & $293 / 154$ & $/ 83$ & & $552 / 1214$ & $10.6 / 13.4$ \\
\hline 4 & $519 / 303$ & $/ 143$ & & $524 / 800$ & $8.6 / 12.1$ \\
\hline 5 & $248 / 91$ & $/ 91$ & & $469 / 579$ & $16.9 / 39.2$ \\
\hline 6 & $1269 / 223$ & 10 & & $1269 / 1545$ & $14.5 / 63.8$ \\
\hline 7 & $827 / 372$ & $/ 325$ & & $772 / 1489$ & $16.3 / 62.1$ \\
\hline 8 & $632 / 389$ & $/ 99$ & & $855 / 1242$ & $16.7 / 52.8$ \\
\hline 9 & $1379 / 1020$ & $/ 138$ & & $1241 / 1655$ & $3.7 / 9.0$ \\
\hline 10 & $413 / 264$ & 165 & & $524 / 1379$ & $8.1 / 81.5$ \\
\hline 11 & $496 / 248$ & $/ 223$ & & $524 / 662$ & $32.3 / 108.8$ \\
\hline 12 & $993 / 524$ & $/ 41$ & & $413 / 855$ & $4.8 / 7.4$ \\
\hline 13 & $579 / 331$ & $/ 28$ & & $551 / 938$ & $3.3 / 12.1$ \\
\hline 14 & $827 / 579$ & 496 & $/ 358$ & $744 / 1048$ & $18.0 / 74.0$ \\
\hline 15 & $496 / 262$ & $/ 102$ & & $386 / 1021$ & $4.6 / 18.0$ \\
\hline 16 & $607 / 259$ & $/ 63$ & & $331 / 882$ & $27.7 / 111.0$ \\
\hline 17 & $1765 / 1214$ & $/ 1103$ & $/ 39$ & $855 / 1214$ & $4.4 / 35.5$ \\
\hline 18 & $1655 / 496$ & 662 & & $2014 / 2924$ & $9.0 / 29.7$ \\
\hline 19 & $607 / 358$ & $/ 243$ & & $359 / 1462$ & $6.8 / 11.7$ \\
\hline 20 & $827 / 80$ & $/ 80$ & & $828 / 1766$ & $6.6 / 46.0$ \\
\hline 21 & $800 / 160$ & $/ 985$ & $/ 259$ & $635 / 993$ & $14.1 / 29.1$ \\
\hline 22 & $1021 / 1076$ & $/ 276$ & & $745 / 1573$ & $13.2 / 154.1$ \\
\hline 23 & $800 / 800$ & $/ 469$ & $/ 138$ & $910 / 1379$ & $20.2 / 55.5$ \\
\hline 24 & $1158 / 441$ & $/ 113$ & & $607 / 882$ & $22.0 / 44.0$ \\
\hline 25 & $358 / 248$ & $/ 108$ & & $303 / 910$ & $23.8 / 45.1$ \\
\hline 26 & $1214 / 1186$ & $/ 1186$ & & $1186 / 1379$ & $32.1 / 38.3$ \\
\hline 27 & $910 / 524$ & $/ 331$ & & $690 / 1076$ & $10.6 / 41.2$ \\
\hline 28 & $1076 / 882$ & $/ 524$ & & $524 / 1020$ & $8.8 / 31.3$ \\
\hline
\end{tabular}

petrosal sinuses performed to precisely localize the source of the ACTH excess and facilitate hemihypophysectomy in cases without a distinct microadenoma.

\section{Sampling technique}

A venous catheter was inserted in a forearm vein for serial blood sampling. A saline infusion was used to prevent obstruction of the catheter by clotting. Blood samples were then drawn in 20 -min intervals for $24 \mathrm{~h}$. The patient was allowed to sleep during the night and was not isolated from other patients, so that the normal daily rhythm was, as far as possible, not altered. The blood tubes contained Ca-EDTA and aprotinin. The samples were kept in an ice-water bath until centrifugation, and the plasma was kept frozen at $-80 \mathrm{C}$ until assayed.

\section{Hormone determination}

Serum cortisol concentrations were assayed in duplicate using a commercially available RIA (Becton-Dickinson, Heidelberg, Germany). Normal basal values ranged from 275-579 nmol/L. Values below 28 $\mathrm{nmol} / \mathrm{L}$ were considered below the limit of assay detection.

Plasma ACTH concentrations were determined in duplicate on silicic acid-extracted samples by a specific RIA with an N-terminal antibody. Synthetic human ACTH-(1-21) (Synacthen, Sandoz, Basel, Switzerland) was used as standard. Normal basal values ranged from 4.4-11 pmol/ L. Values below $0.9 \mathrm{pmol} / \mathrm{L}$ were considered to be below the assay detection limit (5).

\section{Transsphenoidal microsurgery}

Transsphenoidal sella exploration and selective adenomectomy were performed as described previously (4). A standard sublabio-paraseptaltranssphenoidal approach to the sella turcica was used. In all cases, a careful microsurgical exploration of the intrasellar structures was performed. The pituitary body was serially sectioned in the coronal and sagittal planes. In 26 patients, tissue that was considered adenomatous was resected. In 2 cases, no microadenoma was detected, and a hemihypophysectomy was performed according to the ACTH gradient during inferior petrosal sinus sampling. The resected tissue was fixed with formalin, embedded in paraffin, and assessed by conventional and immunostaining for pituitary hormones by light microscopy. As soon as a suspected adenoma was resected, infusion therapy with hydrocortisone was commenced. The sella floor was closed by a fascia lata transplant.

\section{Postoperative testing}

All patients were followed up for at least $2 \mathrm{yr}$. Retesting was performed 7-10 days, 3 months, and 2 yr after surgery by determination of basal plasma ACTH and cortisol and cortisol suppressibility after overnight low dose ( $2 \mathrm{mg}$ ) dexamethasone testing. Patients were considered to be in remission if clinical improvement and normal suppression of cortisol (to $<55 \mathrm{nmol} / \mathrm{L}$ ) after low dose dexamethasone were found (4). The status of disease at the latest follow-up visit was used to determine the persistence of hypercortisolism or (lasting) remission.

\section{Statistical analysis}

All data on pulsatile secretion of cortisol and ACTH obtained during the preoperative sampling were processed by the computerized pulse detection program Cluster $(6,7)$. $t$ values to assess significant pulses were set at 2.0 and 2.0. A cluster of two peaks was used to define a peak and a nadir.

\section{Patient grouping}

Patients were grouped into those found to have a pituitary tumor and those without a tumor. Another grouping was performed on the criterion of whether a remission occurred after the operation. This classification, thus, resulted in four overlapping groups of patients. These were retrospectively examined in terms of pulsatile ACTH and cortisol secretion patterns. As there are no well defined limits for classifying a secretion pattern as hyper- or hypopulsatile, this distribution was performed in a simplified manner by orientation of the respective parameter to the mean value obtained for the whole collective. Values above this parameter were arbitrarily classified as hyperpulsatile; values below were classified as hypopulsatile. The significance of the individual parameters (Tables 2 and 3 ) was tested by comparing the mean values of the pulsatility parameters by Student's $t$ test. However, for the distribution of the hyper- and hypopulsatile secretion patterns to the various groups of patients (Tables 4 and 5), the $\chi^{2}$ test was used.

\section{Results}

With two exceptions, preoperative dynamic endocrine testing of the patients revealed the classical findings of Cushing's

TABLE 2. Twenty-four-hour profiles of ACTH and cortisol secretion: patients with/without adenoma (Cluster analysis)

\begin{tabular}{lccc}
\hline & $\begin{array}{c}\text { No. of sig- } \\
\text { nificant } \\
\text { peaks }\end{array}$ & $\begin{array}{c}\text { Mean absolute } \\
\text { peak (pmol/L) }\end{array}$ & $\begin{array}{c}\text { Mean relative } \\
\text { increase in } \\
\text { significant } \\
\text { peaks }\end{array}$ \\
\hline $\begin{array}{l}\text { ACTH } \\
\text { Patients with adenoma }\end{array}$ & $5.95 \pm 5.24$ & $19.4 \pm 17.0$ & $1.98 \pm 1.24$ \\
Patients without adenoma & $4.71 \pm 3.95$ & $17.3 \pm 13.5$ & $1.93 \pm 1.81$ \\
$P$ & NS & NS & NS \\
$\begin{array}{l}\text { Cortisol } \\
\text { Patients with adenoma }\end{array}$ & $3.95 \pm 2.36$ & $725 \pm 427$ & $1.66 \pm 0.75$ \\
Patients without adenoma & $4.00 \pm 3.46$ & $910 \pm 215$ & $1.86 \pm 0.50$ \\
$P$ & NS & NS & NS \\
\hline
\end{tabular}

Values are the mean $\pm \mathrm{SD}$. 
TABLE 3. Twenty-four-hour profiles of ACTH and cortisol secretion: patients with/without remission (Cluster analysis)

\begin{tabular}{|c|c|c|c|}
\hline & $\begin{array}{l}\text { No. of sig- } \\
\text { nificant } \\
\text { peaks }\end{array}$ & $\begin{array}{c}\text { Mean absolute } \\
\text { peak ht } \\
\text { (pmol/L) }\end{array}$ & $\begin{array}{l}\text { Mean relative } \\
\text { increase in } \\
\text { significant } \\
\text { peaks }\end{array}$ \\
\hline \multicolumn{4}{|l|}{ ACTH } \\
\hline Patients with remission & $6.56 \pm 5.44$ & $18.9 \pm 18.3$ & $2.00 \pm 1.34$ \\
\hline Patients without remission & $4.00 \pm 3.43$ & $18.8 \pm 11.8$ & $1.92 \pm 1.48$ \\
\hline$P$ & NS & NS & NS \\
\hline \multicolumn{4}{|l|}{ Cortisol } \\
\hline Patients with remission & $3.67 \pm 2.38$ & $720 \pm 463$ & $1.66 \pm 0.81$ \\
\hline Patients without remission & $4.50 \pm 3.03$ & $863 \pm 196$ & $1.80 \pm 0.43$ \\
\hline$P$ & NS & NS & NS \\
\hline
\end{tabular}

Values are the mean \pm SD.

TABLE 4. Twenty-four-hour profiles of ACTH and cortisol secretion: hypopulsatile and hyperpulsatile secretion patterns in patient groups with/without adenoma

\begin{tabular}{lcc}
\hline & \multicolumn{2}{c}{ Patients } \\
\cline { 2 - 3 } & Adenoma & No adenoma \\
\hline ACTH & 12 & 4 \\
Hypopulsatile pattern & $\mathbf{9}$ & 3 \\
Hyperpulsatile pattern & & \\
Cortisol & 10 & 4 \\
Hypopulsatile pattern & 11 & 3 \\
Hyperpulsatile pattern & \\
\hline
\end{tabular}

TABLE 5. Twenty-four-hour profiles of ACTH and cortisol secretion: hypopulsatile and hyperpulsatile secretion patterns in patient groups with/without remission

\begin{tabular}{lcc}
\hline & \multicolumn{2}{c}{ Patients } \\
\cline { 2 - 3 } & Remission & No remission \\
\hline ACTH & 11 & 5 \\
Hypopulsatile pattern & 7 & 5 \\
$\quad$ Hyperpulsatile pattern & & \\
Cortisol & 8 & 5 \\
$\quad$ Hypopulsatile pattern & 10 & 5 \\
Hyperpulsatile pattern & & \\
\hline
\end{tabular}

disease. One patient (no. 2) did not have an abolished diurnal cortisol rhythm, and in another (no. 26), 50\% suppression of serum cortisol did not occur after overnight high dose dexamethasone treatment. This latter patient had petrosal sinus sampling carried out to document that the pituitary gland was the source of the ACTH excess.

In 18 of the patients (no. 1-18), transsphenoidal microsurgery achieved a lasting remission from Cushing's disease. In this group of patients, selective adenomectomy was performed, and an ACTH-secreting microadenoma was immunohistochemically documented. Among the 10 patients with persistent disease after surgery (no. 19-28), ACTH-secreting microadenomas were immunohistochemically documented in only 3 cases (nos. 22, 25, and 27). In one of these cases, the tumor was found to be invasive into the cavernous sinus (no. 27) and, thus, surgically uncurable for technical reasons. In 1 case (no. 28), the resected specimen histologically represented nodular hyperplasia of ACTH-secreting cells. No adenoma was found during pituitary microsurgery in 6 cases, and biopsies of either the pituitary gland (in 3 cases) or the hemihypophysectomy specimen (in 3 cases) did not provide evidence of adenomatous tissue.

In comparison of the groups of patients with remission and persistence of the disease and in the groups with and without a pituitary adenoma found during transsphenoidal sella exploration, there was no significant difference in any one of the parameters, in contradiction to the hypothesis of van Cauter and Refetoff (3). The mean values are reported in detail in Tables 2 and 3 . However, the most striking finding was that both hypopulsatile and hyperpulsatile secretion patterns were encountered in patients with surgically and histologically verified ACTH-secreting pituitary adenomas, the resection of which was followed by a sustained remission of the disease.

Comparison of the patient groups with respect to a hyperpulsatile or hypopulsatile secretion pattern of both hormones, ACTH and cortisol, did not reveal obvious differences between those subjects who were found to harbor an adenoma and those in whom no adenoma could be detected (Table 4). In addition, the distinction between hyper- and hypopulsatile rhythms failed to differentiate those who postoperatively remitted from the disease and those who were found to suffer from persistent hypercortisolism after surgery (Table 5).

\section{Discussion}

The results of this study demonstrate that analysis of the pulsatile secretion of ACTH and cortisol has little prognostic value in preoperative assessment of patients with Cushing's disease. Our study shows that daily ACTH and cortisol secretion profiles do not allow the prediction of postoperative outcome or of whether a tumor will be found during surgery. Our findings are, therefore, in marked contradiction to the hypothesis of van Cauter and Refetoff (3), who suggested that Cushing's disease due to an autonomous ACTH-secreting pituitary tumor should exclusively be associated with hypopulsatile secretion patterns. This hypothesis was formulated from the analysis of patients studied in multiple centers and using inhomogenous sampling intervals. The present findings of both hypo- and hyperpulsatile patterns of ACTH and cortisol secretion in patients who were documented to have ACTH-secreting pituitary adenomas and Cushing's disesase by itself refute the intriguing hypothesis of van Cauter and Refetoff. Furthermore, when Liu et al. (8) compared daily profiles of ACTH and cortisol secretion, they found that a hyperpulsatile secretion pattern of ACTH does not necessarily lead to a hyperpulsatile cortisol secretion pattern. Similar findings were described by Gallagher $e t$ al. (9), Krieger and Allen (10), and Schürmeier (11). The present study further shows that this dissociation is frequently found, as documented by Tables 4 and 5, which compile data on the hyper- and hypopulsatile secretion patterns of ACTH and cortisol in relation to whether an adenoma was found and whether the patient remitted. Liu et al. (8) suggest a variable sensitivity of the adrenal cortex to ACTH pulses as an explanation for this dissociation. For individual cases, therefore, one cannot deduce pituitary ACTH pulsatility on 
the basis of pulsatile cortisol secretion. Correspondingly, the daily profiles of cortisol secretion assessed by measuring cortisol in the serum or plasma will not allow reliable conclusions on the intrinsic secretion rhythm of the pituitary gland or the pathophysiology of Cushing's disease in the individual patient.

Furthermore, Gambacciani et al. (12) showed that human fetal and adult pituitary cells in vitro did not continuously secrete a constant amount of $\mathrm{ACTH}$, but developed an organspecific rhythm of ACTH secretion. Because isolated culture was used, these cells were deprived of hypothalamic stimulation and feedback mechanisms. It seems that the pituitary corticotrophs harbor an intrinsic $\mathrm{CRH}$-independent secretion rhythm. Similar findings in in vitro cell culture experiments were described by other groups for the secretion of PRL (13), GH (14), and LH (15). This autonomous pulsatile secretion of isolated pituitary cells as a whole is one further argument that disproves the hypothesis of van Cauter and Refetoff (3). A differentiation between this intrinsic pulsatility rhythm and the rhythm of an underlying hypothalamic pulsatility generator on the basis of variation in plasma ACTH and cortisol rhythms is difficult. Thus, the original source of the pulse rhythm is impossible to trace with the currently available analytical methods.

There are, however, many further problems associated with a study of this episodic character. A large variety of different influences could play a role in generating a hyperpulsatile or hypopulsatile secretion rhythm. Krieger (16) postulated organ-specific intrinsic day rhythms in the hypothalamus, pituitary gland, and adrenal cortex. Clinical observations in patients with Cushing's disease suggest that the sensitivity of the feedback system may exhibit cyclic changes (17). Low frequency secretion patterns with cycles lasting for weeks (18) and even intermittent short phases of remission (19) may occur.

Other biochemical assessments have proven to be equally disappointing in helping to differentiate the different pathophysiologies of Cushing's disease $(20,21)$. None of the routinely used preoperative tests appear to be of diagnostic value, and the responses of cortisol and ACTH to CRH do not significantly differ in patients with hypothalamic or pituitary Cushing's disease (22). CRH measurements performed during venous blood samling from the petrosal sinus also are of limited value (23).

One problem with the present study was that the amount of blood minimally required to determine ACTH by a radioimmunological technique after an extraction procedure limited more frequent sampling, i.e. in shorter intervals. Application of a recently developed immunoradiometric assay technique (24) for measuring ACTH would offer some advantage in this respect.

Although the development of a method to differentiate between hypothalamic and pituitary Cushing's disease remains desirable, it is worth noting that pituitary surgery in experienced centers very often leads to clinical remission. Thus, techniques for determining the etiology of Cushing's disease must be carefully evaluated in terms of the extra risks in using an additional invasive procedure in relation to the success rate and side-effects of an operative sella exploration $(4,25)$.

\section{References}

1. Liddle GW. 1960 Tests of the pituitary-adrenal suppressibility in the diagnosis of Cushing's syndrome. J Clin Endocrinol Metab. 20:1539-1561.

2. Müller OA, Stalla GK, von Werder K. 1983 Corticotropin releasing factor: a new tool for the differential diagnosis of Cushing's syndrome. J Clin Endocrinol Metab. 57:227-229.

3. van Cauter E, Refetoff S. 1985 Evidence for two subtypes of Cushing's disease based on the analysis of episodic cortisol secretion. N Engl J Med. 312:1343-1349.

4. Fahlbusch R, Buchfelder M, Müller OA. 1986 Transsphenoidal surgery for Cushing's disease. J R Soc Med. 79:262-269.

5. Müller OA, Fink R, Baur X, Ehbauer M, Madler M, Scriba PC. 1978 ACTH im Plasma: Extrackion und Bestimmung. GIT Labormedizin. 2:117.

6. Royston JP. 1989 The statistical analysis of pulsatile hormone secretion data; Clin Endocrinol (Oxf). 30:201-210.

7. Veldhuis JD, Johnson ML. 1986 Cluster analysis: a simple versatile, and robust algorithm for endocrine pulse detection. Am J Physiol. 250:E486-E493.

8. Liu JH, Kazer RR, Rasmussen DD. 1987 Characterization of the twenty-four hour secretion patterns of ACTH and cortisol in normal women and patients with Cushing's disease. J Clin Endocrinol Metab. 64:1027-1035.

9. Gallagher TF, Yoshida K, Roffwarg HD, Fukushima DK, Weitzman ED, Hellman L. 1973 ACTH and cortisol secretory patterns in man. J Clin Endocrinol Metab. 36:1058.

10. Krieger DT, Allen W. 1975 Relationship of bioassayable and immunoassayable plasma ACTH and cortisol concentrations in normal subjects and in patients with Cushing's disease. J Clin Endocrinol Metab. 40:675.

11. Schürmeier TH. 1987 On the relationship between ACTH and cortisol secretion. In: Müller $O A$, ed. Corticotropin releasing hormone. Stuttgart: Thieme Verlag; 6-8.

12. Gambacciani M, Liu JH, Swartz WH, Tueros VS, Rasmussen DD, Yen SSC. 1987 Intrinsic pulsatility of ACTH release from the human pituitary in vitro. Clin Endocrinol (Oxf). 26:557-563.

13. Shin SH, Reifel CW. 1981 Adenohypophysis has an inherent property for pulsatile prolactin secretion. Neuroendocrinology. 32:139-144.

14. Stewart JK, Clifton DK, Koercker DJ, Rogol AD, Jaffe T, Goodner CJ. 1985 Puslatile release of growth hormone and prolactin from the primate pituitary in vitro. Endocrinology. 116:1-5.

15. Gambacciani M, Liu JH, Swartz WH, Tueros VS, Yen SS, Rasmussen DD. 1987 Intrinsic pulsatility of luteinizing hormone release from the human pituitary in vitro. Neuroendocrinology. 45:402406.

16. Krieger DT. 1979 Rhythms in CRF, ACTH, and corticosteroids. In: Krieger DT, ed. Endocrine rhythms. New York: Raven Press; pp 123-142.

17. Atkinson AB, Chestnutt A, Crothers E, et al. 1985 Cyclical Cushing's disease: two distinct rhythms in a patient with a basophil adenoma; J Clin Endocrinol Metab. 60:328-332.

18. Liberman B, Waichenberg BL, Tambascia MA, Mesquita CM. 1976 Periodic remission in Cushing's disease with paradoxical dexamethasone response: an expression of periodic hormonogenesis. J Clin Endocrinol Metab. 43:913-918.

19. Bochner F, Burke CJ, Lloyd HM, Nurnberg B. 1979 Intermittent Cushing's disease. Am J Med. 67:507-510.

20. Orth DN. 1985 The old and the new in Cushing's syndrome. N Engl J Med. 310:649-651.

21. Carpenter PC. 1986 Cushing's syndrome: update of diagnosis and managment. Mayo Clinic Proc. 61:49-58.

22. Chrousos GP, Schulte HM, Oldfield EH, Gold PW, Cutler GB, Loriaux DL. 1984 The corticotropin releasing factor stimulation test. N Engl J Med. 310:622-626. 
23. Müller OA, Stalla GK, von Werder K. 1987 CRH in Cushing's syndrome. In: Müller OA, ed. Corticotropin releasing hormone. Stuttgart: Thieme Verlag; 51-58.

24. Raff H, Findling JW. 1989 A new immunoradiometric assay for corticotropin evaluated in normal subjects and patients with Cush- ing's syndrome. Clin Chem. 35:596.

25. Laws ER. 1989 Cushing's disease-neurosurgical viewpoint. In: van Heerden JA, ed. Common problems in endocrine surgery. Chicago: YearBook; 18-22. 